\title{
"Not Just the Great Spirit": Traditional Native American Views of Consciousness
}

\author{
Richard Honeycutt \\ Acoustical Consultant and Independent Researcher, USA
}

\begin{abstract}
Although Native Americans, like many indigenous peoples worldwide, speak of many abstract concepts; consciousness, in an explicit sense, is not one of them. However, by learning their teachings about cosmology, the Good Medicine Path, and healing, we can discover a consistent practical view of consciousness that points toward a truly blessed future. We learn these teachings most effectively not by academic discourse, but by hearing simple stories and comments in the way that the children learn from the grandfathers and grandmothers. Having learned these teachings, we take on the responsibility of living according to our new understanding.
\end{abstract}

Keywords Native Americans, Indigenous, Cherokee, Healing, Consciousness, Respect, Holarchy, Sacred Reciprocity

\section{Introduction}

Consciousness and healing are important topics in our world, but that has not always been a universal condition. So-called modern Western societies are latecomers to the study of consciousness, and their focus is very cerebral. Dr. William Tiller's holarchy of consciousness shown in Figure 1 is an example.

Many investigators find consciousness research futile, since they attempt to find an explanation of consciousness in Material Monism. This is much like trying to find St. Francis of Assisi's love for animals by autopsying his body! In Material Monism, consciousness is an epiphenomenon of the brain. No one has a clue how this could occur. Rutgers University professor of philosophy and cognitive science Jerry Fodor has observed, "Nobody has the slightest idea how anything material could be conscious. Nobody even knows what it would be like to have the slightest idea how anything material could be conscious, so much for the philosophy of consciousness." (Dossey, 1999)

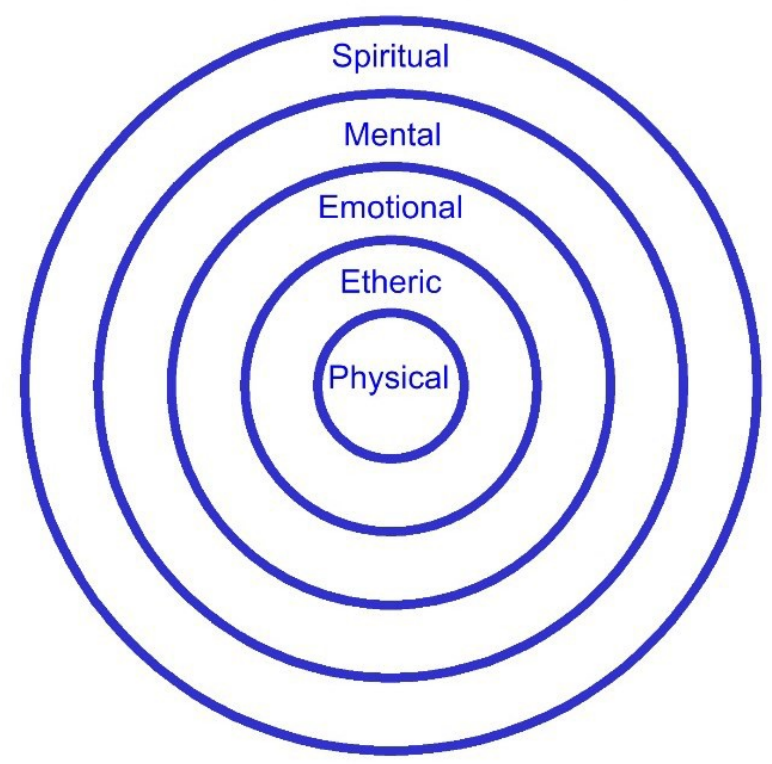

Figure 1. Dr. William Tiller's Holarchy of Consciousness

Eastern studies of consciousness are millennia old, and are very experiential. Yoga and Tai Chi Chuan guide the chela through explorations of expanded states of consciousness.

Traditional Native American views of consciousness are very practical, guiding the seeker toward proper life choices and attitudes, and informing the practice of the indigenous healer. No word that directly translates "consciousness" is to be found in the Cherokee or many other Native American languages, but some comprehension of indigenous views can be derived from their cosmology. Understanding this cosmology does not occur through mental reasoning, but through immersion in the mythopoetic stories taught by the grandfathers to the children. I will do my best to give the reader an idea of the indigenous cosmology. 


\section{First Steps into Indigenous Cosmology}

The Great Spirit is a trinity: he includes aspects of the Formless, the Form-Building, and Father. The Great Spirit creates all that is, and all that is, is alive with the life of the Great Spirit. To be alive is to be conscious. But the consciousness of a stone is different from the consciousness of a human. Stones barely notice us as we flit by in our hurried lives. But we can listen to stones.

There was a young boy who lived when all the people slept in caves. One day, he was walking on what we now call Clingman's Dome, in the Great Smoky Mountains. Gradually, he started feeling sad about his people, and he lay on the rock and cried, "What can I do to help my family and the clan?" He heard a gruff voice say, "I have heard you, and I can help you, if you will listen and learn." Startled, the boy said, "Who are you?" The gruff voice answered, "I am Grandfather Rock, and I am part of your vision to seek answers, and you can hear me because you want to listen. He then shared stories about how to start a fire by rubbing two sticks together over dry leaves. He taught the boy how to make a spear, to ask the fish for food, and to give thanks. The boy, who was becoming a man, returned to his family and shared the gifts from Grandfather Rock.

The consciousness of an eagle is different from the consciousness of a human. When Eagle speaks, he asks, "Do you want to learn how to fly? Do you want to see the great Creation through my eyes? Do you want to dance on the wind as I do? Then dance the dance of life, offering thanks for all things, walking in step with the universe and its eternal movements." Eagle speaks with his eyes, his balance, and his presence. He speaks from the upper world and from the world of Mother Earth.

The consciousness of a squirrel is different from the consciousness of a human. When she sees the great, lumbering humans coming, the squirrel scampers away. When she sees that the nuts and acorns have fallen, she gathers them and stores them for winter food. When the hungry cat approaches, she scolds him from high in her tree, and sometimes she calls her sister to scamper around the tree trunk with her so that the cat thinks he sees a squirrel suddenly disappear from one place and reappear at another.

The consciousness of the deer and the bear are different from the consciousness of a human. The sacred deer represents the mind of the universe. She is cunning, and she sees and hears all things. Bear likes to sleep and to eat when he is hungry. He represents the physical body. When Bear sees Rabbit, he tries to catch and eat him. But he usually fails, because his greed for food has made him fat and slow. Bear stands on his hind legs and looks like a hairy man with claws. Some men are greedy and fat and slow like Bear.

The consciousness of a coyote is different from the consciousness of a human. Coyote is smaller and weaker than bear, but very fast and very tricky. He loves to play jokes on humans and on his prey. He knows that his place is between the rabbit and the bear.

We can learn from stones, the eagles, the squirrel, Deer, Bear, the coyote, all of nature, but doing so requires that we respect Nature. We may not consciously remember what was said when we converse with a stone, but we can respect its ancient wisdom.

Humans also are triune, having body, mind, and spirit. We live in the world of three. Our minds are expressed in our wills, which have three functions: the will to be, compassion for all our relations out to 7 generations, and actualizing (or building) will. Humans have the gift of choice, but we do not always use it. If you carry a handful of chicken feed into the henhouse, the chickens will come to you to be fed. They do not really choose to come to you; they are conditioned to do so. In the same way, we humans often act according to our conditioning, thinking we are choosing.

There are at least three worlds: the physical world, the celestial or spiritual world, and the middle world. Some people have access to the higher worlds. These worlds may be considered to interpenetrate in a holographic sense. Archetypes, or tutelaries from the animal, plant, and spiritual worlds can help us bridge between worlds. The Peruvian Elders say that about $1500 \mathrm{BCE}$, Elders from the Plieades came and taught them how to access the other worlds. Chinese indigenous traditions recount a similar visitation about the same time. A healer must be able to visit the other worlds, but must have the proper protections in place. These protections include right motivation and an "egg" of light surrounding the seeker. The most important aspects of our lives come from the other worlds: life, death, sickness, the rise and fall of governments. To learn our purpose in life, we must fast and pray until we see visions. Most true learning occurs in the dream space between worlds.

Humans are interconnected through two webs of energy: individual webs, and the universal web that passes though the earth. There are evil spirit beings that can use these webs to possess a person and cause psychological, mental, and physical illness.

Body consciousness appears in energy centers which must be balanced and open to free flow. The energy flows from a spiritual source corresponding to the black hole at the center of our galaxy, through our sun, through the sun of our body, the Qosco or lower dan tien, to Mother Earth. (See Figure 2.) We can enhance the flow of energy by visualizing the movement of heat and light along this path. This is the indigenous cosmology. Most modern societies are disconnected from the path because they have no coherent cosmology; they have no shared stories of origin and destination. Heeding the ancestral teachings is the key to restoring a coherent cosmology.

Teachers from the spirit world will come to you when the time is right. When the Spanish Conquistadors tried to tell the Peruvian Elders about Jesus, and showed them paintings of him, they replied, "yes, we know him; we've been working with him for generations!" The 
conquistadors, with their unbalanced ideas of power and their lack of respect for others, had no concept of visionary encounters, and didn't know how to understand what the Elders said.

Health of body, mind, and spirit requires that we live in balance with nature, respecting one another and nature - all our relations. This is called sacred reciprocity, and is the central social and spiritual ordering principle. Most suffering is caused by transgression of sacred reciprocity, which manifests in the physical and subtle realms. Illness often begins in the emotions. To effect healing, we must go to the source of the illness. The healer can absorb the illness into his Qosco and digest it. 95\% of the residue goes into the earth, and $5 \%$ goes to the pineal and pituitary to foster growth.

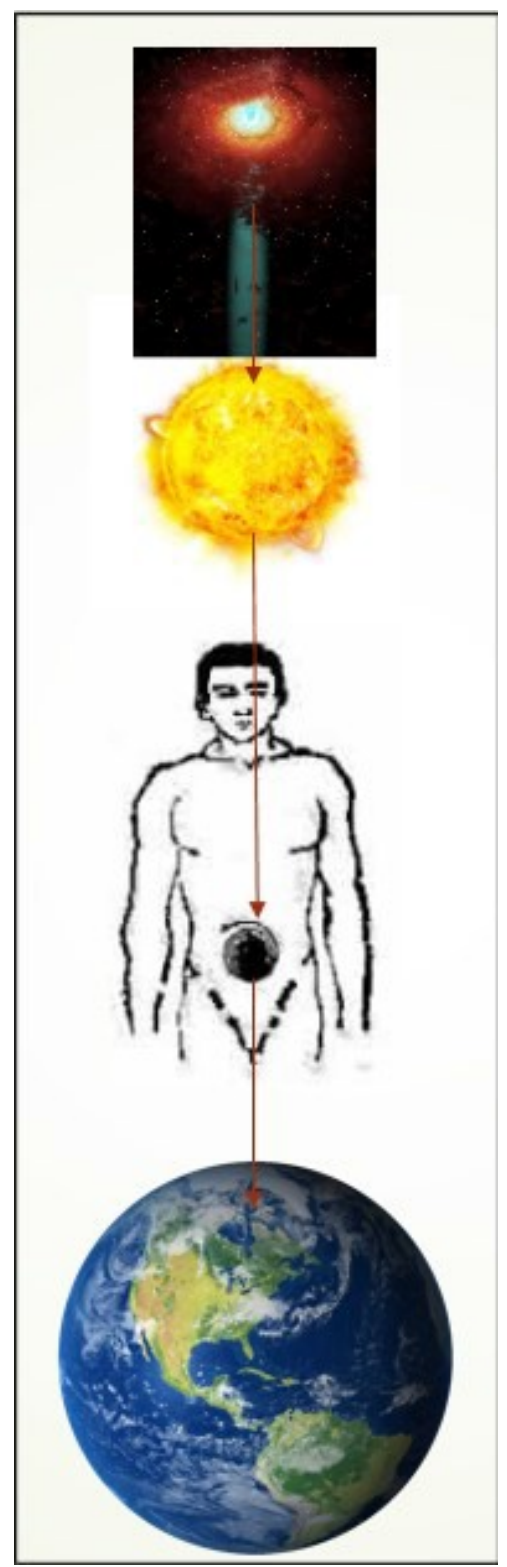

Figure 2. The flow of energy in the human body, according to indigenous tradition

We must accept what others do, even though we may not approve. Retaliation is giving away our power. Sacred reciprocity leads us to live in gratitude, rather than retribution. Balance among dualities is essential. Healing consists of restoring balance.

The healer's path is one of action: the teachings of the Great Spirit come by living them, not by talking about them. The healer may use medicines from the plant, animal, or mineral kingdoms, as well as spiritual and mental approaches. Healers use natural law, but to do so, they must align themselves with natural law. Sometimes adjustments in the healer's attitude are required in order to become aligned with natural law.

The uses of plants can be learned by listening to the plants themselves. A healer can locate the needed medicinal plant under three feet of snow, even if he has never been to that place before.

A healer may not know before treatment what medicine (s)he will use, and may not remember afterward what was used. We have all had times in which we awoke from a dream and wanted to think about the significance of the dream, but we had to empty our bladder first. Upon returning to bed, we could not remember the dream, because the world of the dream is not the world of our bladder. A great medicine man may not talk of "healing" people, because healing" is part of the fabric of the universe. Instead, he may call his role in helping the sick, "doctoring". "Doctoring" includes the practices of intention and visualization; thoughts can be very powerful. The healer must know whether to "doctor" someone or not. He may help to heal one problem, only to have a more serious problem replace it. And the healer himself can take on consequences by "doctoring" when he should not. The sick person's spirit knows whether "doctoring" is needed, and the healer must learn this from the sick person's spirit. Sometimes it is necessary to visit the spirit world while "doctoring". In any case, the patient's faith in the healer is essential.

Every physical object in nature has four energies: physical, mental, spiritual, and natural. If you duplicate an indigenous healer's herbal formula, but do not know the spiritual side, the remedy will not work. The physical is the lowest form of energy, and corresponds to electricity. Mental energy has memory and exists outside the body as well as inside. Spiritual energy requires a high level of calm and connection, achieved by connection with nature. Each form of energy has a male and a female aspect. Since humans have the gift of choice, we cannot change someone else's energy; only interfere with it, in which case we can take on their consequences.

Not all of our lives can be understood from what we and our families recall. We all live many lives, and sometimes remember episodes from previous lives. Sometimes we must learn lessons left over from previous lives. Once an older man raped a young girl, he was caught and taken before the elders. "What should we do with him," the people of the village asked. "Throw him off the mountain, 
the Elders answered. There is not enough time left in his life for him to learn respect since he has none to begin with. He will have to learn respect in another life."

Once there were a husband and wife who loved each other very deeply. One morning, the wife became very angry and she walked quickly away toward the mountains. When the husband got up, he did not find her in the house, so he looked outside and saw her retreating to the mountains. He saw that she was already so far away and walking so quickly, that he could never catch up with her. So he prayed to the Great Spirit: "My wife is leaving, going into the mountains. I don't know anything that I have done wrong, but she walks as if she is very angry. Maybe she is not feeling well." The Great One said, "Are you sure you did not do anything?" The man answered, "I don't know." The Great One then asked, "Did you fail to do something?" The man replied, "I'm not sure. She's getting further and further away, and I do not know what to do." "I know that your love for her is great, and your heart is true," said the Great One. "I will do what I can to slow her down." The man thanked the Great One deeply and continued his journey up the mountain. The Great One caused a huckleberry bush to appear in front of the woman, but she was so angry that she did not notice it. Then he put a blackberry bush in her path so that it would stick to her clothes and slow her down. It did stick to her clothes, but she was so angry that she just kept walking quickly away. "Aha," the Great One thought, "I must make her look down in humility before she will stop and listen to what is in her heart." So he put a little plant in the ground that hid a luscious, sweet-smelling fruit that was shaped like a heart. When the woman got to the plant, she got down on her knees to find out what it was that smelled so well. When she bowed her head to pick one of the fruits and saw the beautiful heart-shaped berries, she let go of her anger, and forgot why she has been angry in the first place.

The first thing that she thought of was to pick some of these delicious strawberries for her husband, whom she loved with all her heart. She picked only the smaller ones so that the big ones could grow, and she thanked Mother Earth for this special gift. Before long, she saw her husband coming to meet her. Excitedly, she ran to meet him, and they hugged each other for a very long time in the setting sun. Then she gave him the bright red strawberries she had picked for him, and together they gave thanks to the Great One that they were reunited.

The woman thought about how sad she would have been to never see her husband again. She told him she would never leave him, and just then, noticed that the little strawberries were very fragile, yet very beautiful. The man and woman were thankful for their love, and together they enjoyed the sweet, juicy strawberries that the Great Spirit had provided to Mother Earth.

Today, many humans have broken their relationship with each other, and some have broken their relationship with nature. The initial break between humans and nature may have occurred with the beginnings of agriculture, when insects became no longer our relations, but our enemies. All that is, is alive, and all that is alive is related to us. The most negative moral statement that a Native American can make of a man is to say, "He acts as if he had no relations." The acknowledgement and respect for all our relations, out to the seventh generation, is central to the "good-medicine way", the balanced path of life taught by the indigenous peoples. Note that they do not say, "He has no relations," just as they did not say that the white men were mean and dishonest, since judging in that way is thought to lock people into their faults. Instead, they called the white men "those who act like mean men."

Western anthropologists might say I have spoken to you of stones, eagles, deer, bears, squirrels, coyotes, rapists, and berries. Or have I spoken of harmony with nature and learning from nature, how anger can hide our true selves from us, about respect and gratitude?

When humans were first made, the animal spirits and the plant spirits, who had been made earlier, held a council. They decided to offer their bodies for humans to eat, provided that the humans lived in sacred reciprocity by showing gratitude and respect. But the humans forgot to respect the animals and plants by asking permission before killing them for food, and they forgot to show gratitude for the food. So the animal spirits held a council. Deer said, "Since the humans do not show respect and gratitude when they kill us, I will make them suffer from arthritis." Bear said, "and I will give them rheumatism." The other animal spirits made similar pledges. When the plants heard what the animals had done, they said, "humans are still young and ignorant, and we feel sorry for them. We will give our bodies so that humans can be healed from arthritis and rheumatism and the other illnesses the animals have decided to send". And so it is today: when humans kill and eat thoughtlessly, showing no respect and gratitude, they develop illnesses. When they pay the proper attention to plants in their diets and in their medicine, they can find healing from illnesses.

The world over, indigenous peoples say we are living in a time long prophesied. Glaciers melting are a sign of this. The "rainbow tribe" prophecy speaks of a coming together of peoples from diverse cultures. In this coming together, we must develop balance and show respect for all our relations!

\section{Discussion}

In a recent seminar I presented, one of the participants asked, "Just what do you mean by "consciousness"'? It was an excellent question. The meaning that one attaches to "consciousness" depends heavily upon one's metaphor or paradigm for reality. The word can mean "awareness", "spirit", "ground of being", sentience, the ability to feel, having a sense of selfhood, and the ability to control one's mind. "Awareness" is certainly not a valid definition, since 
people in coma are definitely not aware of their surroundings, yet some people have awakened from coma and described in detail things that occurred in the room while they were comatose, implying that they were unaware but not unconscious. Goswami has stated, "Definitions are possible in terms of concepts only, and all concepts are secondary to consciousness." Another way to understand the difficulty in defining "consciousness" is by comparison with multi-dimensional geometries: a shape in a geometry whose number of dimensions is $\mathrm{N}$ can only be correctly perceived from a vantage point in a geometry having $\mathrm{N}=1$ or more dimensions. Referring back to Tiller's holarchy of consciousness in Figure 1, we could consider all that extends beyond the spiritual sphere as being consciousness. In order to define consciousness, according to this metaphor, we would have to be able to perceive from some sort of "trans-consciousness" level. (Some theists might equate this level with God; others may consider "consciousness" the same as God.) For our purposes, perhaps the best we can do is to recognize that a useful definition of "consciousness" would probably include at least ability to respond to stimuli and to control one's mind.

The indigenous peoples have often been studied through the lens of religion, although few of them would dissect their thinking into sacred and secular components. Although "religion" is another word that is hard to define, it is generally associated with ritual. The Native American rituals are performed to bring about certain physical, mental, and emotional states, and to express relationship, not to please a deity. Only to the extent that religion is relational is it valid to consider the "good medicine path" taught by the Native Americans to be religious. The Great Spirit responded to the abandoned husband's distress out of love and compassion.

As discussed earlier in this paper, respect for all one's relations and sacred reciprocity are the central ordering principles. These principles are based upon the belief that everything is alive and conscious, and that we can communicate with anything, even a stone. In the indigenous cosmology, the question of whether "communicating" with a stone is essentially an interaction with one's own subconscious mind would never arise. From a practical point of view, the interaction feels like communication and presents useful insights. To try to inject ideas of the conscious, subconscious, and superconscious is to mix metaphors; thus it accomplishes nothing.

${ }^{i}$ Dossey, Larry (1999): Reinventing Medicine, Harper, San Francisco, p. 30 .
The tri-unity of the Great Spirit and of humans is connected to the ideas of lower, middle, and upper worlds in ways that are typically not specified by the indigenous peoples. Animal and plant spirits are thought of as collective in nature: when Deer decided to visit arthritis upon the ungrateful and disrespectful humans, it was the collective spirit of the deer, not a particular deer or even a "king deer". This is one of the ways in which the consciousness of animals and plants differs from that of humans.

On the other hand, the consciousness of humans is similar to that of animals and plants in that human spirits, as well as the collective animal and plant spirits, have free will. Individual animals and plants are not necessarily considered to possess the gift of choice (free will).

In Eastern and some recent Western thought, two ideas appear that are not specifically discussed in publications concerning Native American views of consciousness: the collective unconscious (similar to what Dr. Larry Dossey calls "the One Mind" in his book of that title), and mystical union. I believe that both of these ideas are included in the indigenous view: the collective unconscious is represented as relationship with all that is, and the fulfillment of the Rainbow Prophecy represents a growing realization of the reality of the One Mind. Mystical union is a part of "spirit learning", or visiting other worlds. However, I emphasize that this is only my belief! In the latter decades of the $20^{\text {th }}$ Century, the Native American Elders decided just which of their traditional teachings could be shared with the non-indigenous people. I suspect that specific teachings about the One Mind and mystical union that can occur within that Mind may have been considered too advanced to be shared with the general public, especially those who have no coherent cosmology. Casting pearls before swine can result in harm to both teacher and student!

\section{Acknowledgements}

I gratefully acknowledge the contributions to my understanding of Native American cosmology from Drs. J. T. and Michael Garrett and Jeff Firewalker Schmitt, of the Eastern Band of Cherokee, and from Rolling Thunder, as presented in The Realms of Healing, by Stanley Krippner and Alberto Villoldo (Celestial Arts, Milbrae, 1976.) 